\title{
External nutrient inputs into terrestrial ecosystems of the Falkland Islands and the Maritime Antarctic region
}

\author{
S. Bokhorst · A. Huiskes · P. Convey • \\ R. Aerts
}

Received: 19 January 2007/Revised: 2 April 2007/Accepted: 9 April 2007/Published online: 4 May 2007

(C) Springer-Verlag 2007

\begin{abstract}
Antarctic terrestrial ecosystems are nutrientpoor and depend for their functioning in part on external nutrients. However, little is known about the relative importance of various sources. We measured external mineral nutrient sources (wind blown material, precipitation and guano) at three locations, the cold temperate oceanic Falkland Islands $\left(51^{\circ} 76^{\prime} \mathrm{S}\right)$, and the Maritime Antarctic Signy $\left(60^{\circ} 71^{\prime} \mathrm{S}\right)$ and Anchorage Islands $\left(67^{\circ} 61^{\prime} \mathrm{S}\right)$. These islands differ in the level of vegetation development through different environmental constraints and historical factors. Total mineral nitrogen input differed considerably between the islands. During the 3 month summer period it amounted to $18 \mathrm{mg} \mathrm{N} \mathrm{m}^{-2}$ on the Falkland Islands and 6 and $102 \mathrm{mg} \mathrm{N} \mathrm{m}^{-2}$ at Signy and Anchorage Islands, respectively. The high value for Anchorage was a result of guano deposition. By measuring stable isotopic composition $\left(\delta^{15} \mathrm{~N}\right)$ of the different nitrogen sources and the dominant plant species, we investigated the relative utilisation of each source by the vegetation at each island. We conclude that external mineral nitrogen inputs to Antarctic terrestrial ecosystems show great spatial var-
\end{abstract}

\section{S. Bokhorst $(\bowtie) \cdot$ A. Huiskes}

Netherlands Institute of Ecology, Centre for Estuarine and Marine Ecology, Korringaweg 7,

4401 NT Yerseke, The Netherlands

e-mail: Stefbokhorst@hotmail.com

P. Convey

British Antarctic Survey, Natural Environmental Research

Council, High Cross, Madingley Road,

CB3 0ET Cambridge, UK

R. Aerts

Institute of Ecological Science, Department of Systems Ecology,

Vrije Universiteit, De Boelelaan 1085,

1081 HV Amsterdam, The Netherlands iability, with the local presence of bird (or other vertebrate) colonies being particularly significant.

Keywords Nutrient inputs $\cdot$ Stable isotope $\cdot$ Sea spray

\section{Introduction}

Antarctic terrestrial ecosystems have amongst the least developed soils in the world and are generally nutrient poor (Beyer and Bölter 2000). Nitrogen limitation of plant growth appears to be one of the main factors restricting vegetation development at some locations (Davey and Rothery 1992; Arnold et al. 2003; Wasley et al. 2006). Therefore it is expected that external nitrogen sources may play a major role in the nutrient budget of these ecosystems (Greenfield 1992a). However, only a few studies have investigated the utilisation of these external sources by vegetation in Antarctic terrestrial ecosystems (Greenfield 1992b; Erskine et al. 1998). Large but spatially localised and mostly coastal bird and seal colonies are known to influence vegetation in their vicinity through extra nitrogen deposition (Lindeboom 1984; Staley and Herwig 1993; Crittenden 1998). Penguin colonies, in particular, are associated with large guano deposits. When such colonies become unoccupied or move to other sites the abandoned rookeries form a nutrient rich area for plants and mosses (Tatur et al. 1997).

Not all Antarctic locations experience a large direct influence from penguin or other vertebrate colonies, because many areas are inaccessible for such animals. These areas are often vegetated, but are thought to receive lower nitrogen input than vegetation closer to such colonies. These remote ecosystems are thought to be dependent for their nitrogen on precipitation, wind blown material, such as 
sea spray, and occasional guano from passing birds (Holdgate 1967; Smith 1985; Ryan and Watkins 1989; Cocks et al. 1998). In order to understand and quantify the major sources and pathways of nitrogen flow in Antarctic terrestrial ecosystems it is, therefore, imperative to develop a better description of the main external sources of nutrients.

Nitrogen use in ecosystems can be tracked by investigating the concentrations of the stable isotope, ${ }^{15} \mathrm{~N}$. Plants that take up nitrogen from sources with a certain ${ }^{15} \mathrm{~N}$ signature will normally obtain a signature that closely resembles that of the source (Robinson 2001; Dawson et al. 2002). However, plants can take up nitrogen from different sources, and the consequential mixing of these different signatures may lead to uncertainty in the identity of the source. Fractionation during uptake and transport may further obscure the signal. However, if the ${ }^{15} \mathrm{~N}$ signal of a major source is distinct, it still is possible to determine this distinct nitrogen source in the plants (Erskine et al. 1998). Precipitation, wind blown material, soils and guano potentially have distinct stable isotope signatures. Large differences in stable isotope composition are already known to exist between mosses and lichens from the Antarctic (Galimov 2000; Huiskes et al. 2006). These differences partly result from the utilisation of different nitrogen sources by these cryptogams (Crittenden 1998; Wainright et al. 1998). Analyses of the different potential sources of nitrogen for their ${ }^{15} \mathrm{~N}$ content should, therefore, provide clarification of the origin of external nitrogen into these ecosystems.

This study aims to provide a better description and understanding of external nitrogen sources that are potentially utilised by the vegetation in Maritime Antarctic terrestrial ecosystems. We have investigated this by quantifying mineral nitrogen sources and by analysing the stable isotope $\left(\delta^{15} \mathrm{~N}\right)$ composition of these sources. By comparing the stable isotope values of the different sources with that of the dominant species in the vegetation we have attempted to identify their main external nitrogen sources. Furthermore, Antarctic terrestrial ecosystems are normally less developed at higher latitudes (Peck et al. 2006), and the influence of external sources might be expected to be more pronounced and distinct in less complex ecosystems. By comparing the relative importance of different external nitrogen sources along a latitudinal gradient we attempt a preliminary study to test this hypothesis.

\section{Materials and methods}

Study sites

The study took place at three islands along a latitudinal gradient, during the austral summers of 2004/2005 and
2005/2006. Coastal vegetation was sampled from a dwarf shrub habitat on the Falkland Islands $\left(51^{\circ} 76^{\prime} \mathrm{S} 59^{\circ} 06^{\prime} \mathrm{W}\right)$ and from cryptogamic (moss and lichen) vegetation on Signy Island (South Orkney Islands, $60^{\circ} 71^{\prime} \mathrm{S} 45^{\circ} 59^{\prime} \mathrm{W}$ ) and Anchorage Island (Marguerite Bay, western Antarctic Peninsula, $67^{\circ} 61^{\prime} \mathrm{S} 68^{\circ} 22^{\prime} \mathrm{W}$ ).

The Falkland Islands study site is adjacent to a marine inlet on the western part of East Falkland where, due to the typically high winds, sea spray is often blown inland. The nearest significant bird colonies (cormorant, Phalacrocorax magellanicus) are within $0.5-1.0 \mathrm{~km}$, but visual inspection suggested that they only have a direct influence on the vegetation in their immediate $(<10 \mathrm{~m})$ vicinity.

At Signy Island, moss and lichen vegetation close to the British Antarctic Survey (BAS) research station was examined. Signy Island hosts a large number of penguins (Pygoscelis papua, P. adeliae and P. antarctica), elephant seals (Mirounga leonina) and fur seals (Arctocephalus gazella) (Hodgson et al. 1998; Lynnes et al. 2004). The nearest concentrations of elephant seals to the study site are within $500 \mathrm{~m}$, across Borge Bay at Cemetery and Elephant Flats, and these contained more than 100 animals on some occasions. Large penguin colonies are within $2 \mathrm{~km}$ on the Gourlay Peninsula, to the south of the study site, while the island also hosts a large number of cliff and burrow-nesting petrels, storm petrels and prions, and ground nesting skuas. Of the three islands, Anchorage Island includes the least developed terrestrial ecosystems, in terms of macroscopic vegetation. The study site selected here is at the eastern side of a rocky ridge, at approximately $30-40 \mathrm{~m}$ asl. There is one beach used by elephant seals for moulting and haul out on the island, c. $500 \mathrm{~m}$ south east of the site, typically with 10-20 individuals present at any one time during the summer, and c. 30 pairs of south polar skuas (Catharacta maccormicki) nest in the vicinity.

Logistical practicalities

Due to logistical scheduling constraints and practicalities, field periods at the three sites were restricted. Each year the Falkland Islands were visited during spring between the end of October and the end of November, Signy Island in mid summer between December and mid-January, and Anchorage Island in late summer between mid-January and the end of February. At each site, field collections and measurements were restricted to these 6-week periods.

\section{Sampling of potential nutrient sources}

Plants and cryptogams are capable of taking up mineral nitrogen in the form of $\mathrm{NH}_{4}$ and $\mathrm{NO}_{3}$ as well as more complex organic compounds (Aerts and Chapin 2000). 
However, due to possible fractionation of ${ }^{15} \mathrm{~N}$ during uptake of more complex substrates we have decided to focus on the mineral nitrogen sources alone to link source and plants more directly.

\section{Wind blown material}

Two aerosol samplers (Fig. 1) were deployed at each of the experimental sites. Each sampler incorporated a paper filter $\left(0.04 \mathrm{~m}^{2}\right)$ which was held facing into the wind by a wind vane. During the fieldwork periods spent on each site, the filters were replaced weekly. Control filters ( $n=6$ for each site) were placed in the aerosol sampler, immediately removed after placement and treated similarly as the other filters. Collected (wet) filters were stored in sealed plastic jars and transported to the Netherlands at $-20^{\circ} \mathrm{C}$. After thawing, the filters were rinsed with demineralised water and this water was analysed for mineral nitrogen (using a segmented flow analyser) and ${ }^{15} \mathrm{~N}$. Only the ${ }^{15} \mathrm{~N}$ of the $\mathrm{NH}_{4}$ obtained was analysed, as the $\mathrm{NO}_{3}$ concentration in the samples was found to be too low for this analysis. No visible particles were observed on the filters.

\section{Precipitation}

Precipitation at each site was collected by a self-registering precipitation gauge (PLUVIO), which was emptied at the

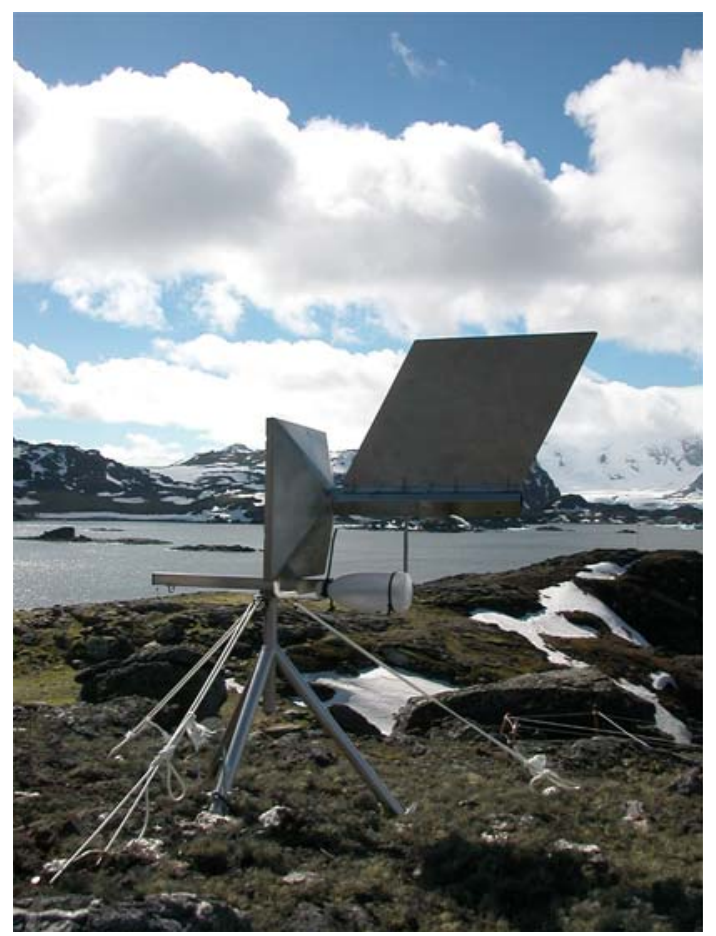

Fig. 1 Sampler of wind blown material on the Signy Islands beginning, during the field period and end of each field period. At the Falkland Islands, this took place at the beginning and end of November, on Signy Island at the beginning and end of December and on Anchorage Island at the end of January and mid-February. Collected precipitation was stored at $-20^{\circ} \mathrm{C}$ and transported to the Netherlands for analyses of mineral nitrogen and ${ }^{15} \mathrm{~N}$. No additives were added to reduce microbial growth during transport. Due to the high winds and consequently high evaporation at the Falkland Islands we were unable to obtain a large enough precipitation sample for analyses of ${ }^{15} \mathrm{~N}$ and, unfortunately, the samples from Anchorage Island were lost during transport. For the estimation of total mineral nitrogen in the Anchorage Island precipitation, we therefore used the data obtained from Signy Island. Longterm mean annual precipitation data on the Falkland Islands $\left(575 \mathrm{~mm} \mathrm{year}^{-1}\right)$ were obtained from the Department of Agriculture of the Falkland Islands Government. Signy (400 mm year ${ }^{-1}$ ) and Anchorage Island $(500 \mathrm{~mm}$ year $^{-1}$ ) mean annual precipitation figures were obtained from Holdgate (1967) and Turner (2002).

\section{Bird guano}

In order to estimate the amount of nitrogen deposition on land through bird excreta, four plastic tarpaulins $\left(48 \mathrm{~m}^{2}\right.$ in total) were placed on the ground during the 2004/2005 and 2005/2006 field seasons at each site. Each day, guano deposition events were counted and the deposited material collected. The samples were stored at $-20^{\circ} \mathrm{C}$ and transported to the Netherlands for analysis of total nitrogen content (elemental analyser) and stable isotopes $\left({ }^{15} \mathrm{~N}\right)$. As birds are not present, at least at the Antarctic sites, yearround, the estimates of total nitrogen deposition were based on a presence of 3 months (Rootes 1988). Guano encountered on the tarpaulins at the Falkland Islands was too small to permit sufficient amounts to be obtained for analyses.

Vascular plant, cryptogam and soil analyses

Samples of the dominant vascular plant (roots only) and cryptogam species (Table $1, n=3$ for each species) were collected from each field site during the 2004/2005 season. The lichen species studied do not contain cyanobacterial photobionts and therefore do not fix nitrogen themselves (Ovstedal and Smith 2001). Samples of 1-2 g were stored in sealed glass jars and transported to the Netherlands at $20^{\circ} \mathrm{C}$ where, after freeze-drying, they were ground and analysed for ${ }^{15} \mathrm{~N}$ using a Fisons NA 1500 elemental analyzer coupled to a Finnigan conflo II interface, and a Finnigan MAT Delta $\mathrm{S}$ isotope ratio mass spectrometer (IRMS). 
Table 1 Species sampled for ${ }^{15} \mathrm{~N}$ analysis from the three sites

\begin{tabular}{lll}
\hline Falkland Islands & Signy Island & Anchorage Island \\
\hline Empetrum rubrum $(\mathrm{v})(-3.6 \pm 1.7)$ & Polytrichum strictum $(\mathrm{m})(7.6 \pm 0.2)$ & Sanionia uncinata $(\mathrm{m})(8.5 \pm 1.0)$ \\
Pernettya pumilla $(\mathrm{v})(3.6 \pm 0.2)$ & Chorisodontium aciphyllum $(\mathrm{m})(4.6 \pm 0.6)$ & Pohlia nutans $(\mathrm{m})(15.1 \pm 0.4)$ \\
Oxalis enneaphylla $(\mathrm{v})(-1.9 \pm 0.4)$ & Andreaea depressinervis $(\mathrm{m})(1.7 \pm 0.6)$ & Brachytheciurn austrosalebrosum $(\mathrm{m})(15.8 \pm 0.3)$ \\
Blechnum penna-marina $(\mathrm{v})(-2.9 \pm 0.6)$ & Cladonia gracilis $(\mathrm{l})(2.6 \pm 0.2)$ & Cephaloziella varians $(\mathrm{liv})(11.9 \pm 0.0)$ \\
& Ochrolechia frigida $(\mathrm{l})(2.1 \pm 1.2)$ & Usnea antarctica $(1)(-1.8 \pm 1.5)$ \\
& Cetraria aculeata $(\mathrm{l})(-5.6 \pm 1.3)$ & Umbilicaria decussata $(1)(6.7 \pm 1.0)$ \\
& Usnea antarctica $(\mathrm{l})(-7.1 \pm 0.7)$ & Xanthoria elegans $(1)(7.1 \pm 0.2)$ \\
& Umbilicaria decussata $(1)(-7.9 \pm 1.4)$ & Burellia sp. $(1)(7.4 \pm 0.4)$ \\
& Sphaerophorus globosus $(1)(-1.9 \pm 0.4)$ & Acarospora macrocyclos $(1)(10.2 \pm 0.1)$ \\
& & Rhizoplaca aspidophora $(1)(10.7 \pm 1.0)$
\end{tabular}

Values between brackets are $\delta^{15} \mathrm{~N}$ values with se

$v$ Vascular plant, $m$ moss, 1 lichen, liv liverwort

Soil samples were collected under each of the vegetation communities at the three sites during the 2005/2006 season, frozen $\left(-20^{\circ} \mathrm{C}\right)$, and transported to the Netherlands for analyses of stable isotopes $\left({ }^{15} \mathrm{~N}\right)$. The term 'soil' as applied to the Antarctic moss communities is here taken as the layer underneath the vegetation, mainly composed of partly decomposed moss peat.

\section{Calculations and statistical analyses}

Mineral nitrogen inputs from the different external sources were expressed as $\mathrm{mg} \mathrm{N} \mathrm{m}{ }^{-2}$ week $^{-1}$. Then, total external nitrogen input during the summer period (13 weeks) was estimated by multiplying the measured mean weekly amounts by 13. An estimate of nitrogen input in precipitation over the same period was based on a quarter of the mean annual precipitation at each site.

Isotopic ratios $\left({ }^{15} \mathrm{~N} /{ }^{14} \mathrm{~N}\right)$ were converted to delta units $(\delta)$ in parts per thousand, using the formula:

$\delta=\left(R_{\text {sample }} / R_{\text {standard }}-1\right) 1000$

in which $R$ is molar ratio of heavy to light isotopes $\left({ }^{15} \mathrm{~N} /{ }^{14} \mathrm{~N}\right)$. The accepted standard ratio for nitrogen is that of atmospheric air $\left({ }^{15} \mathrm{~N} /{ }^{14} \mathrm{~N} \approx 3.67 \times 10^{-3}\right.$ ) (Dawson et al. 2002)

Differences between sites in input from external nitrogen sources were analysed using one-way ANOVA. As the bird guano nitrogen input at Anchorage Island was very large in comparison with the other sites, differences were examined with and without inclusion of this source. Differences in $\delta^{15} \mathrm{~N}$ between sources and plant species were analysed with a one-way ANOVA. Where necessary, a log transformation was applied to compensate for non-homogeneity of variance. Analyses were completed using the programme Statistica 7.0 (Statsoft, Inc., http://www.statsoft.com).

\section{Results}

External nitrogen sources

The total amount of external mineral nitrogen $\left(\mathrm{NH}_{4}\right.$ and $\mathrm{NO}_{3}$ ) input differed substantially between the sites and was highest $(P<0.05)$ for Anchorage Island and lowest for Signy Island, with intermediate levels at the Falkland Islands (Fig. 2). This pattern was largely a result of the high nitrogen input through guano at Anchorage Island. When comparing external mineral nitrogen sources, based on precipitation and wind blown material alone that of the

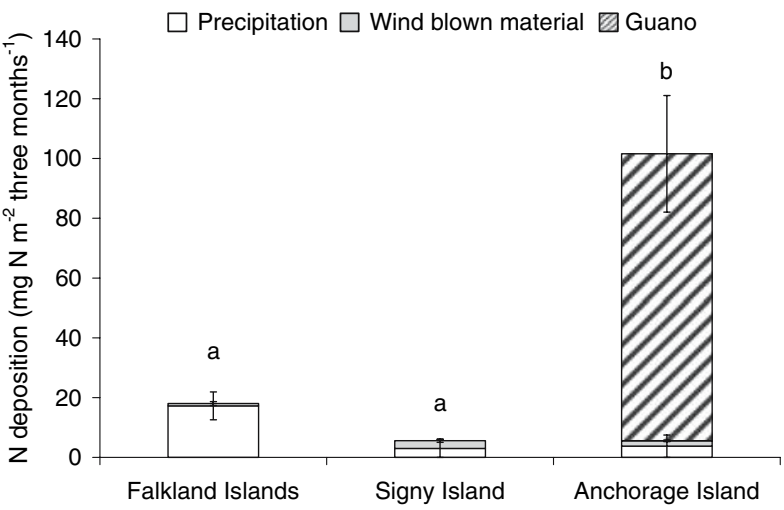

Fig. 2 Estimated mineral nitrogen input due to precipitation, wind blown material and guano for the three Islands during the summer period (3 months). Different letters indicate significant $(P<0.05$ Tukey HSD) differences between the Islands. $n=$ (at least) 3 , error bars are se 
Falkland Islands was marginally higher $(P<0.1)$ than the Maritime Antarctic Islands.

Stable isotope composition of vegetation and external nitrogen sources

Table 2 summarises the stable isotope values of the external nitrogen sources from each island. $\delta^{15} \mathrm{~N}$ values of the plant species at the Falkland Islands were almost all below $0 \%$, with the exception of the roots of Pernettya pumilla, but did not differ significantly from any of the external sources (Fig. 3a). At Signy Island, species in the moss community had $\delta^{15} \mathrm{~N}$ values that were similar to the soil and wind blown material but significantly higher $(P<0.05)$ than that of precipitation. The lichen genera Usnea, Umbilicaria and Cetraria had significantly lower $(P<0.05) \delta^{15} \mathrm{~N}$ values than those of wind blown material and soil. The $\delta^{15} \mathrm{~N}$ values of Andreaea (moss species), Sphaerophorus and Ochrolechia did not differ from any of the external sources (Fig. 3b). Wind blown material at Anchorage Island, had higher $(P<0.05) \delta^{15} \mathrm{~N}$ values than the lichens and mosses. $\delta^{15} \mathrm{~N}$ value of guano was not significantly different to those of the moss species examined, though was higher $(P<0.05)$ than that of the lichen Usnea. The moss values did not differ from that of soil, while the lichen $\delta^{15} \mathrm{~N}$ values were lower $(P<0.05)$ (Fig. 3c).

\section{Discussion}

Our estimates of external mineral nitrogen inputs were necessarily limited to the summer period only. Thus, our data refer to the period when the vegetation is most active, as Antarctic species have a short growing season limited to

Table 2 Stable isotope values of external nitrogen sources

\begin{tabular}{llll}
\hline & $\begin{array}{l}\text { Falkland } \\
\text { Islands }\end{array}$ & $\begin{array}{l}\text { Signy } \\
\text { Island }\end{array}$ & $\begin{array}{l}\text { Anchorage } \\
\text { Island }\end{array}$ \\
\hline Soil & $0.0(0.1)^{\mathrm{a}}$ & $6.2(0.7)^{\mathrm{a}}($ moss $)$ & $14.0(0.3)^{\mathrm{a}}$ \\
& & $9.7(0.7)^{\mathrm{a}}$ (lichen) & \\
Sea water & $2.7(1.3)^{\mathrm{a}}$ & $\mathrm{ND}$ & $1.9(0.5)^{\mathrm{b}}$ \\
Wind blown material & $19.7(8.5)^{\mathrm{a}}$ & $4.4(4.7)^{\mathrm{a}}$ & $20.4(1.3)^{\mathrm{c}}$ \\
Precipitation & $\mathrm{ND}$ & $6.4(1.1)^{\mathrm{a}}$ & $\mathrm{ND}$ \\
Guano & - & - & $10.9(1.9)^{\mathrm{a}}$ \\
\hline
\end{tabular}

Difference letters indicate significant $(P<0.05$ Tukey HSD) differences between sources for each island separately. Values between brackets are se. Moss and lichen refer to the vegetation above the soils samples taken at Signy Island

$N D$ not determined, - not present the summer months (Peck et al. 2006). Total mineral nitrogen inputs found in this study were almost two times lower than found at other studies at Signy Island (Christie 1987; Greenfield 1992a). These differences may result from the different sampling sites, indicating a high variability even within a small region, the potentially crude measurements by our methods used or that we only focussed on mineral nitrogen and did not determine organic nitrogen. Although this could potentially lead to an underestimate of total nitrogen input to each site, the relative importance of the different mineral nitrogen sources, which was the emphasis of this work, for the vegetation can be compared on the basis of the data obtained here.

During the summer months, the mineral nitrogen input through precipitation and wind blown material was similar across the three islands. However, Anchorage Island received a much greater total input through guano deposition by skuas. This finding gives an explicit demonstration that the presence of vertebrates such as skuas can have a major impact on the nutrient balance of Antarctic ecosystems, as also proposed by various other studies (Lindeboom 1984; Erskine et al. 1998). Parallel findings are also reported in ecosystems at lower latitudes (Mizutani and Wada 1988; Polis and Hurd 1996; Post et al. 1998).

The great difficulty in using natural abundance stable isotope signatures in identifying nitrogen sources lies in the potential mixing and fractionation processes that can occur during uptake by plants. However, fractionation during uptake should act to reduce ${ }^{15} \mathrm{~N}$ levels, thereby leading to lower signature values in the plant than that of the source. In cases where an important nitrogen source has a distinct and high ${ }^{15} \mathrm{~N}$ signature compared to other sources, a relatively high ${ }^{15} \mathrm{~N}$ signature would still be expected in the vegetation (see Erskine et al. 1998 and Pearson et al. 2000).

The ${ }^{15} \mathrm{~N}$ contents of the external sources at the Falkland Islands and Signy Island did not differ significantly due to the inherently high variability in their signatures, which inevitably constrains our ability to determine the predominant sources used by vegetation at these study sites. However, at Signy Island, most lichens had a significantly lower signature than that of the wind blown material, indicating that they are unlikely to rely on this source of nitrogen. Their signature was more similar to that of precipitation, from which many lichens are known to obtain nutrients (Greenfield 1992b; Crittenden 1998; Hyvarinen and Crittenden 1998), rather than soil (Ellis et al. 2004).

The two positive $\delta^{15} \mathrm{~N}$ signatures found in this study were from the moss Andreaea depressinervis and the lichen Ochrolechia frigida (Fig. 3b). The positive value of A. depressinervis indicates that this species probably relies on a source other than precipitation such as soil (Ayres et al. 2006). Ochrolechia frigida grows epiphytically on A. depressinervis and had a very similar $\delta^{15} \mathrm{~N}$ value to the 


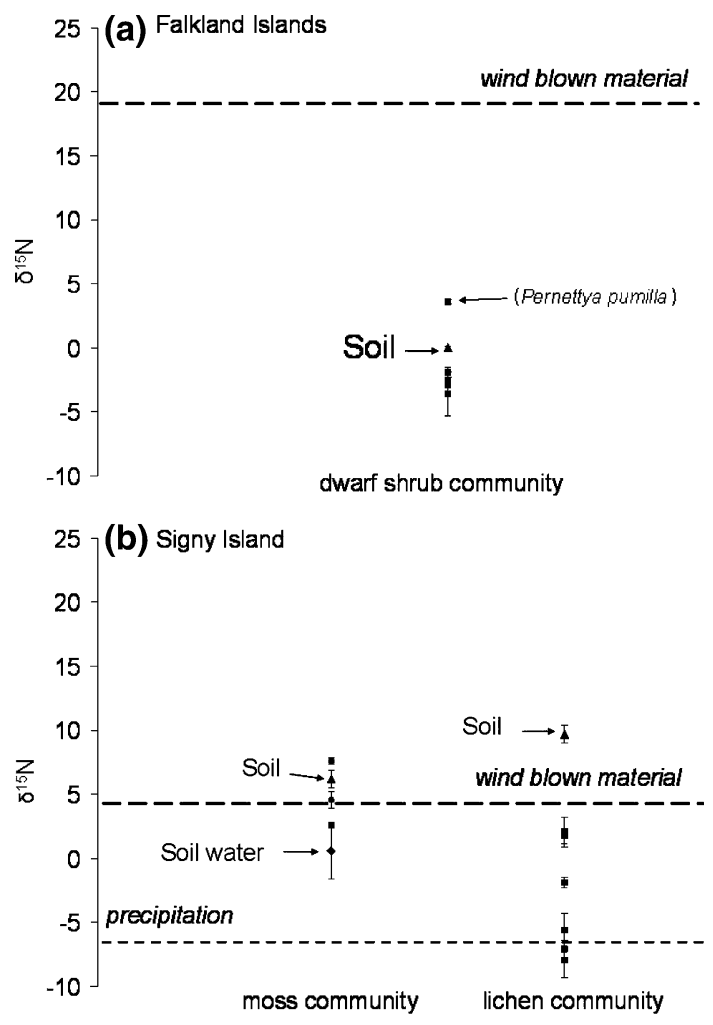

(c) Anchorage Island

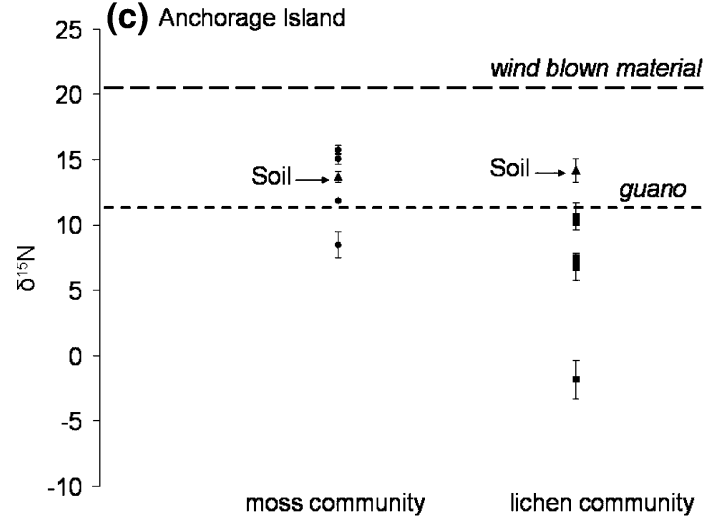

Fig. 3 Stable isotope $\left(\delta^{15} \mathrm{~N}\right)$ values of the dominant plants species in the vegetation (see Table 1 for species names), soil and potential nitrogen sources for the Falkland Islands (a), Signy Island (b) and Anchorage Island (c). The isotopic signatures of wind blown material, bird guano, and precipitation are indicated by dotted lines. $n=3$, error bars are se

moss. This finding supports the proposal that this lichen is parasitic on the moss, as has been suggested by Gassmann and Ott (2000).

Assuming that fractionation leads to lower $\delta^{15} \mathrm{~N}$ values, it is likely that the moss species do not rely on precipitation as a main source of mineral nitrogen at Signy Island. The positive $\delta^{15} \mathrm{~N}$ signature of the wind blown material at this site is likely to be related to the presence of seal and penguin colonies on the island. Indeed, close to the field site on Signy Island there is an elephant seal colony, downwind of which a strong ammonium odour can be detected (SB, personal observation), indicative of a potential nitrogen source (Lindeboom 1984; Greenfield 1992a; Theobald et al. 2006). Other studies have reported that windblown material close to $(<1 \mathrm{~km})$ a penguin colony is usually increased in ${ }^{15} \mathrm{~N}$, with comparable values being present in local vegetation (Erskine et al. 1998).

Nitrogen isotopic content in sea spray was not measured at this location but, given the similarity between samples obtained from the Falkland Islands and Anchorage Island, it seems reasonable to assume a similar ${ }^{15} \mathrm{~N}$ of $2 \%$ for Signy Island. If correct, then it remains impossible to differentiate between sea spray playing an insignificant role as a nitrogen source, or wind-blown material being greatly reduced in ${ }^{15} \mathrm{~N}$ content by combination with sea spray.

In contrast with the data obtained from the Falkland Islands and Signy Island, mineral nitrogen sources at Anchorage Island did differ from one another in isotopic content. The high $\delta^{15} \mathrm{~N}$ value of wind-blown material found here most probably relates to the proximity of a seal haul out area close to the study site and the density of the local skua population. The ${ }^{15} \mathrm{~N}$ signature of the sea water was around $2 \%$, and does not appear to have influenced the signature of wind-blown material to any extent, further suggesting that sea spray alone does not represent a significant mineral nitrogen source for this community.

The high positive $\delta^{15} \mathrm{~N}$ values obtained from vegetation at this site indicate that guano and wind blown material are the major mineral nitrogen sources for this community. One lichen species, Usnea antarctica, did not follow this pattern, having a negative $\delta^{15} \mathrm{~N}$ signature. This low $\delta^{15} \mathrm{~N}$ value indicates that Usnea antarctica probably relies more on precipitation as a nitrogen source, as discussed above for the lichens of Signy Island. The other lichen species probably take up nitrogen from the guano or wind blown material as they had higher $\delta^{15} \mathrm{~N}$ values.

In conclusion, this study demonstrates that external mineral nitrogen inputs to Antarctic terrestrial ecosystems show great spatial variability, with the local impact of vertebrate presence being particularly important. In the absence of such vertebrates, precipitation is a significant mineral nitrogen source for some (but not all) plant species, as also proposed by Greenfield (1992a). We were unable to differentiate the relative importance of sea spray, as distinct from other wind blown material, to these ecosystems. Any direct link involving nutrient transfer between the marine ecosystem and the terrestrial biome does not appear to be very strong at these sites, with transfer rather being largely indirect, mediated by the activities of marine mammals and birds. 


\section{References}

Aerts R, Chapin FS (2000) The mineral nutrition of wild plants revisited: a re-evaluation of processes and patterns. Adv Ecol Res 30:1-67

Arnold RJ, Convey P, Hughes KA, Wynn-Williams DD (2003) Seasonal periodicity of physical factors, inorganic nutrients and microalgae in Antarctic fellfields. Polar Biol 26:396-403

Ayres E, van der Wal R, Sommerkorn M, Bardgett RD (2006) Direct uptake of soil nitrogen by mosses. Biol Lett 2:286-288

Beyer L, Bölter M (2000) Chemical and biological properties, formation, occurrence and classification of Spodic Cryosols in a terrestrial ecosystem of East Antarctica (Wilkes Land). Catena 39:95-119

Christie P (1987) Nitrogen in two contrasting Antarctic Bryophyte Communities. J Ecol 75:73-93

Cocks MP, Balfour DA, Stock WD (1998) On the uptake of ornithogenic products by plants on the inland mountains of Dronning Maud Land, Antarctica, using stable isotopes. Polar Biol 20:107-111

Crittenden PD (1998) Nutrient exchange in an Antarctic macrolichen during summer snowfall snow melt events. New Phytol 139:697-707

Davey MC, Rothery P (1992) Factors causing the limitation of growth of terrestrial algae in Maritime Antarctica during late summer. Polar Biol 12:595-601

Dawson TE, Mambelli S, Plamboeck AH, Templer PH, Tu KP (2002) Stable isotopes in plant ecology. Annu Rev Ecol Syst 33:507559

Ellis CJ, Crittenden PD, Scrimgeour CM (2004) Soil as a potential source of nitrogen for mat-forming lichens. Can J Bot 82:145149

Erskine PD, Bergstrom DM, Schmidt S, Stewart GR, Tweedie CE, Shaw JD (1998) Subantarctic Macquarie Island-a model ecosystem for studying animal-derived nitrogen sources using N-15 natural abundance. Oecologia 117:187-193

Galimov EM (2000) Carbon isotope composition of Antarctic plants. Geochim Cosmochim Acta 64:1737-1739

Gassmann A, Ott S (2000) Growth strategy and the gradual symbiotic interactions of the lichen Ochrolechia frigida. Plant Biol 2:368 378

Greenfield LG (1992a) Precipitation nitrogen at Maritime Signy Island and Continental Cape-Bird, Antarctica. Polar Biol 11:649-653

Greenfield LG (1992b) Retention of precipitation nitrogen by Antarctic mosses, lichens and Fellfield soils. Antarct Sci 4:205-206

Hodgson DA, Johnston NM, Caulkett AP, Jones VJ (1998) Palaeolimnology of Antarctic fur seal Arctocephalus gazella populations and implications for Antarctic management. Biol Conserv 83:145-154

Holdgate MW (1967) Signy Island. Philos Trans R Soc Lond B Biol Sci 252:173-177

Huiskes AHL, Boschker HTS, Lud D, Moerdijk-Poortvliet TCW (2006) Stable isotope ratios as a tool for assessing changes in carbon and nutrient sources in Antarctic terrestrial ecosystems. Plant Ecol 182:79-86

Hyvarinen M, Crittenden PD (1998) Relationships between atmospheric nitrogen inputs and the vertical nitrogen and phosphorus concentration gradients in the lichen Cladonia portentosa. New Phytol 140:519-530

Lindeboom HJ (1984) The nitrogen pathway in a penguin rookery. Ecology 65:269-277

Lynnes AS, Reid K, Croxall JP (2004) Diet and reproductive success of Adelie and Chinstrap penguins: linking response of predators to prey population dynamics. Polar Biol 27:544-554

Mizutani H, Wada E (1988) Nitrogen and carbon isotope ratios in seabird rookeries and their ecological implications. Ecology 69:340-349

Ovstedal DO, Smith RIL (2001) Lichens of Antarctica and South Georgia. University Press, Cambridge

Pearson J, Wells DM, Seller KJ, Bennett A, Soares A, Woodall J, Ingrouille MJ (2000) Traffic exposure increases natural N-15 and heavy metal concentrations in mosses. New Phytol 147:317-326

Peck LS, Convey P, Barnes DKA (2006) Environmental constraints on life histories in Antarctic ecosystems: tempos, timings and predictability. Biol Rev 81:75-109

Polis GA, Hurd SD (1996) Linking marine and terrestrial food webs: Allochthonous input from the ocean supports high secondary productivity on small islands and coastal land communities. Am Nat 147:396-423

Post DM, Taylor JP, Kitchell JF, Olson MH, Schindler DE, Herwig BR (1998) The role of migratory waterfowl as nutrient vectors in a managed wetland. Conserv Biol 12:910-920

Robinson D (2001) Delta N-15 as an integrator of the nitrogen cycle. Trends Ecol Evolut 16:153-162

Rootes DM (1988) The status of birds at Signy Island, South Orkney Islands. Br Antarct Surv Bull 80:87-119

Ryan PG, Watkins BP (1989) The influence of physical factors and ornithogenic products on plant and arthropod abundance at an Inland Nunatak group in Antarctica. Polar Biol 10:151-160

Smith RIL (1985) Nutrient cycling in relation to biological productivity in Antarctic and Sub-Antarctic terrestrial and freshwater ecosystems. In: Siegfried WR, Condy PR, Laws RM (eds) Antarctic nutrient cycles and food webs. Springer, Berlin

Staley JT, Herwig RP (1993) Degradation of particulate organic material in the Antarctic. In: Friedmann EI (ed) Antarctic microbiology. Wiley-Liss, New York

Tatur A, Myrcha A, Niegodzisz J (1997) Formation of abandoned penguin rookery ecosystems in the Maritime Antarctic. Polar Biol 17:405-417

Theobald MR, Crittenden PD, Hunt AP, Tang YS, Dragosits U, Sutton MA (2006) Ammonia emissions from a Cape fur seal colony, Cape Cross, Namibia. Geophys Res Lett 33

Turner J, Lachlan-Cope TA, Marshall GJ, Morris EM, Mulvaney R, Winter W (2002) Spatial variability of Antarctic Peninsula net surface mass balance. J Geophys Res Atmos 107

Wainright SC, Haney JC, Kerr C, Golovkin AN, Flint MV (1998) Utilization of nitrogen derived from seabird guano by terrestrial and marine plants at St Paul, Pribilof Islands, Bering Sea, Alaska. Mar Biol 131:63-71

Wasley J, Robinson SA, Lovelock CE, Popp M (2006) Climate change manipulations show Antarctic flora is more strongly affected by elevated nutrients than water. Glob Change Biol 12:1800-1812 